\title{
A System for Harvesting Eggs from the Pink-Spotted Lady Beetle
}

\author{
Margaret L. Allen and Eric W. Riddick \\ National Biological Control Laboratory, USDA-ARS, 59 Lee Road, Stoneville, MS 38776, USA \\ Correspondence should be addressed to Eric W. Riddick, eric.riddick@ars.usda.gov
}

Received 11 December 2011; Accepted 15 January 2012

Academic Editor: John Heraty

Copyright ( 2012 M. L. Allen and E. W. Riddick. This is an open access article distributed under the Creative Commons Attribution License, which permits unrestricted use, distribution, and reproduction in any medium, provided the original work is properly cited.

\begin{abstract}
We describe a system for harvesting eggs from a predatory insect, the pink-spotted lady beetle, Coleomegilla maculata De Geer (Coleoptera: Coccinellidae). Adult beetles placed in square, transparent containers that included oviposition substrates hanging from the top of the cage deposited eggs on the materials provided. We harvested eggs from these substrates in quantities sufficient for either destructive sampling or synchronous development of larvae. We evaluated effects of crowding inside cages; effects of a chemical attractant on oviposition behavior; egg cannibalism. Females preferred a textured surface rather than a smooth, waxy one for laying eggs. Crowding inhibited oviposition of beetles. Presence of a chemical attractant (methyl salicylate) did not significantly improve oviposition. This paper describes an inexpensive system for harvesting eggs from C. maculata. Refinement of this system should improve oviposition and reduce cannibalism.
\end{abstract}

\section{Introduction}

The pink-spotted lady beetle, Coleomegilla maculata De Geer (Coleoptera: Coccinellidae), is a generalist predator native to North America [1]. In nature, it feeds on a wide range of softbodied insects and mites, and plant products (e.g., pollen, bean leaf tissue [2]) in managed and unmanaged landscapes [3-6]. In its native range, $C$. maculata does not overwinter in houses or become a nuisance pest. C. maculata is amenable to rearing, which makes it a good prospect for commercial production and genetics studies. Although several diets for C. maculata have been described for specific purposes [2, 713] and used in risk assessment studies [14], there is no single-standardized artificial food available for this species. Furthermore, cage systems for rearing C. maculata on a large scale are virtually unknown.

Our goal in this study was to develop a technique to harvest eggs of this predatory species in quantities sufficient for RNA/DNA extraction or large-scale production of insects for release studies or augmentative biological control. The oviposition behavior of $C$. maculata in a natural environment is well studied [6]. Females prefer ovipositing on plants with epidermal hairs (trichomes) on leaf surfaces rather than plants with smooth surfaces, devoid of trichomes [15,
16]. In laboratory conditions, individual females oviposit on smooth surfaces such as containers of food or water [7] or on the smooth surface of a Petri dish or other enclosures [8]. Removal of these eggs from the dish surface is possible but time consuming and often damages the eggs, resulting in poor-quality samples for downstream processes such as nucleic acid extractions (personal observation). Thus, one goal for an artificial system was to identify an oviposition substrate that could encourage oviposition and facilitate successful harvesting of eggs. Methyl salicylate (MeSA) is a common herbivore-induced plant volatile that attracts beneficial insects in many crops [17, 18]. It has been shown to attract at least one lady beetle [19]; however, the potential to stimulate or promote oviposition is unknown.

Cannibalism often occurs in the field and in the laboratory [8], which suggests that this behavior is an adaptive strategy for this species [20]. Thus, eggs are a challenge to obtain because both larvae and adults cannibalize them when reared under crowded conditions (personal observation). An additional goal of the research was to identify conditions that decreased cannibalism. We describe a cage system for harvesting lady beetle eggs for ecological and genetics experiments. 


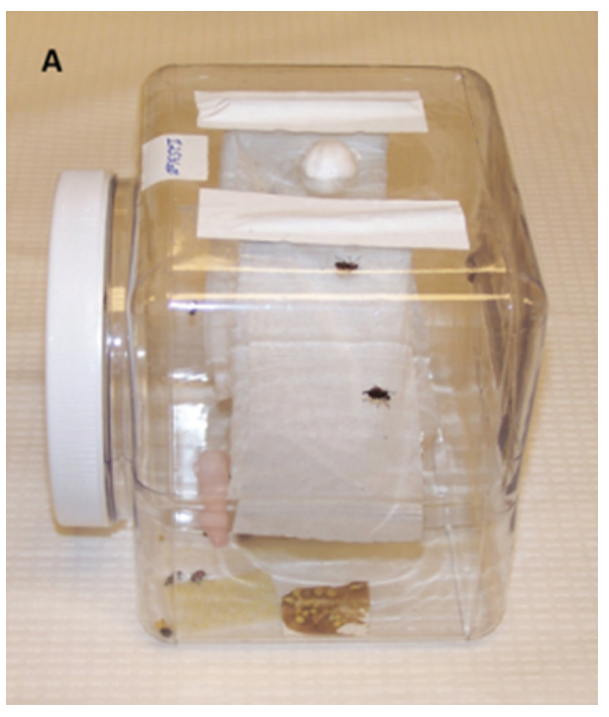

(a)

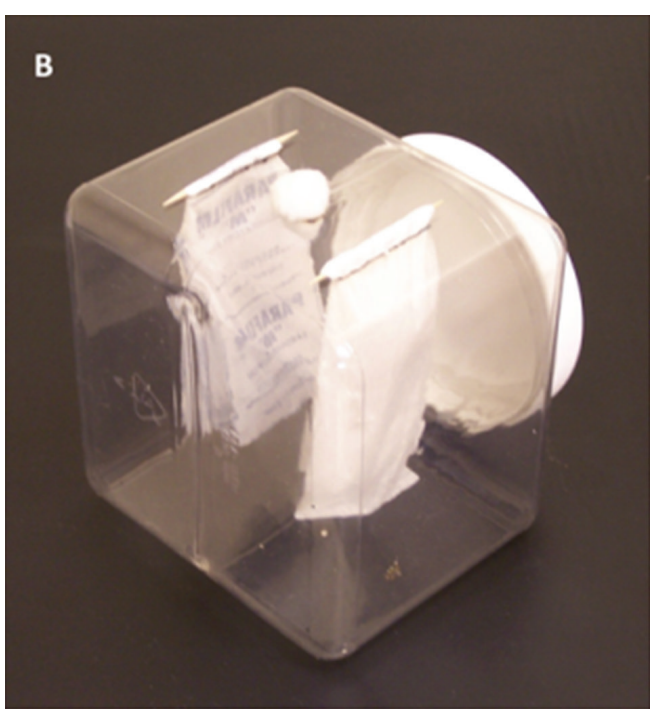

(b)

Figure 1: Enclosures for collecting Coleomegilla maculata eggs: cage for adults including food, water, insects, and hanging oviposition substrates (a) and cage for performing oviposition substrate choice assay (b).

\section{Materials and Methods}

2.1. Insects. We established a laboratory colony of C. maculata from adults in continuous culture from Beltsville, Maryland, USA and Brookings, South Dakota, USA. Predators were cultured initially in standard disposable Petri dishes $(100 \times 15 \mathrm{~mm})$, until populations demanded larger containers. Adult and larval stages were fed a combination of foods including bee pollen (Y. S. Organic Bee Farms, Sheridan, IL, USA), Brewer's yeast, honey, powdered sugar, and Daphnia (Hikari Bio-Pure, Hayward, CA, USA), and live eggs of plant bugs (Lygus lineolaris Palisot de Beauvois or Lygus hesperus Knight) in excess. We provided a free source of water on cotton balls in microcentrifuge tubes $(1.5 \mathrm{~mL}$ capped with cotton) at the base of each cage. We maintained insects in an environmental chamber with a 16L: 8D lighting schedule at $23^{\circ} \mathrm{C}$ and $55 \% \mathrm{RH}$ during the day and $20.5^{\circ} \mathrm{C}$ and $52 \%$ RH during the night.

2.2. Cages. Adult cages were clear plastic containers made by Rez-Tech Company (Kent, OH, USA). The dimensions of the cage were $14 \mathrm{~cm} \times 14 \mathrm{~cm} \times 15 \mathrm{~cm}$, capacity 2,000 $\mathrm{mL}$. We cut two slits ( $10 \mathrm{~cm}$ long) and a single $2 \mathrm{~cm}$ (diam) hole into one side of the container; oviposition substrates were in the slits (Figures 1(a), 1(b)), at a hanging position. Oviposition substrates were at the top of the cages, at some distance from food sources (at the base of the cage). Our hypothesis was that females would be less likely to cannibalize conspecific eggs if they deposited them on substrates that offered some seclusion away from food sources. To harvest eggs, we simply removed oviposition substrates, examined them, and replaced them with new ones. Females deposited their eggs in distinct masses (batches) on these substrates. We plugged the $2 \mathrm{~cm}$ diameter hole with cotton when not transferring beetles into cages.
2.3. Influence of Substrate Type on Oviposition. Materials tested as oviposition substrates were Kimwipes, providing a textured surface, and the paper backing of Parafilm strips, providing a smooth surface. We used five subsample cages, containing between 25 and 50 adults of similar age, at least $1 \mathrm{wk}$ after adults eclosed. Male-to-female sex ratio was approximately $1: 1$ in all cages. We replaced insects that escaped or died. Each cage contained a set of textured and a set of smooth oviposition substrates of equal surface area (Figure 1(b)) and thus provided equal choice for oviposition. Each set consisted of eight individual sheets. We collected eggs each day (Monday-Friday) for 17 total collection dates. We recorded number of egg masses, number of eggs intact, and those cannibalized. Cannibalized eggs had remnants of eggs left on the substrate (Figure 2). Each day of egg collection represented a single sample, and the five cages provided replication of the treatments per day. We recorded number of egg masses and total eggs produced in each cage. We used total eggs collected from oviposition substrates per day for data analysis.

\subsection{Influence of Crowding on Oviposition and Incidence of} Cannibalism. To determine the influence of crowding on oviposition, we manipulated the number of adults in cages. Adult specimens were reproductively active (10-25 days old) and placed in cages as follows. In the first test, cages contained 100 females with 100 males, 50 females with 50 males, 25 females with 25 males, or 10 females with 10 males for a total of 4 cages. In the second test, a single cage contained 20 females with 20 males, 20 females without males, 10 females with 10 males, or 10 females without males for a total of 4 cages. Because of the large number of males and females manipulated in this experiment (in 8 total cages), it was not practical to use the cage as the source of replication. Using Kimwipes tissue as oviposition substrate 


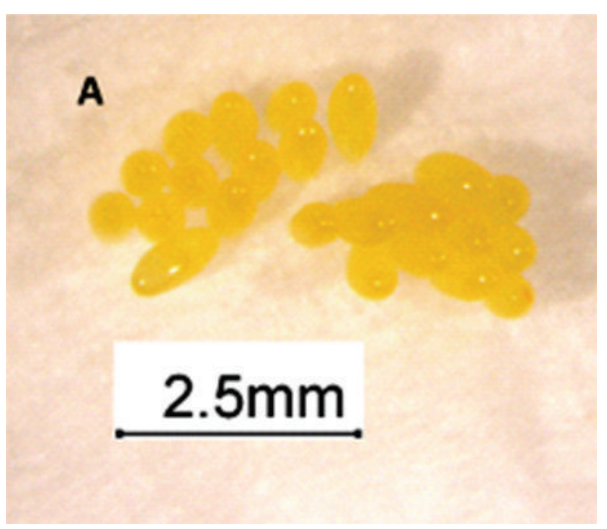

(a)

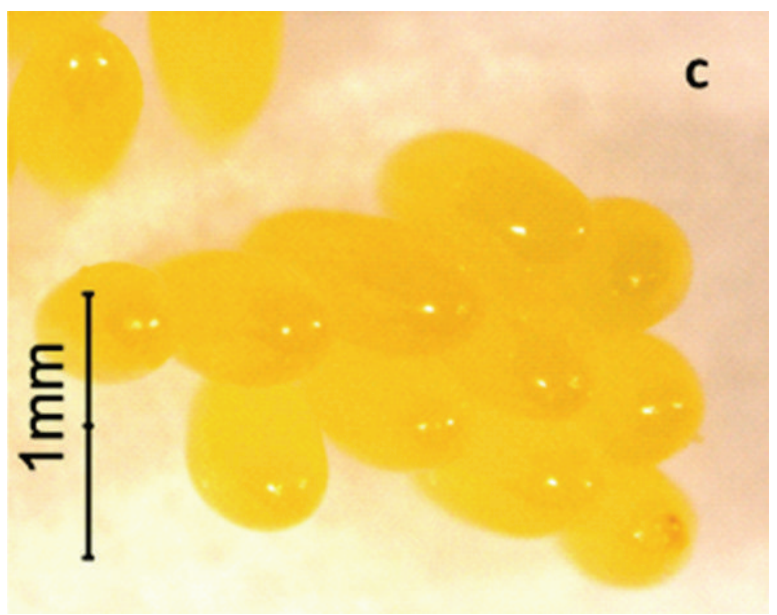

(c)

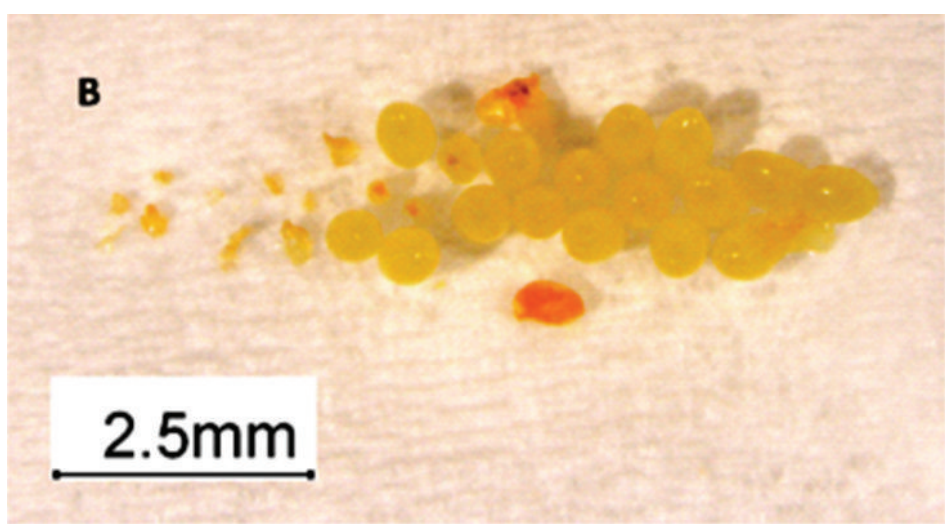

(b)

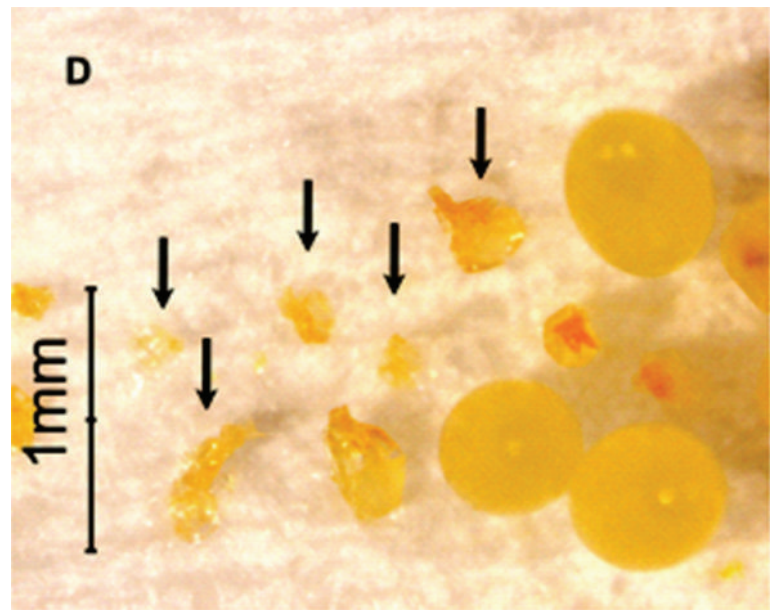

(d)

FIGURE 2: Intact (noncannibalized) eggs of C. maculata in a mass (a, c) and cannibalized eggs in a mass (b, d). Arrows indicate remnants of cannibalized eggs on substrate $(\mathrm{d})$.

based on results from the study described above, we collected eggs from oviposition substrates from each of these cages for 10 consecutive days. Two sets of hanging oviposition substrate were used in each cage (see Figure 1(a)). We recorded number of egg masses and total eggs produced in each cage. We also estimated number of eggs cannibalized as previously described. We used total eggs collected from oviposition substrates per day for data analysis.

2.5. Influence of an Attractant on Oviposition. An arena was constructed from clear plastic containers of two sizes, the size mentioned above and a central chamber approximately twice as large, $14 \mathrm{~cm} \times 14 \mathrm{~cm} \times 30 \mathrm{~cm}$, capacity $4000 \mathrm{~mL}$, connected by clear plastic tubes. We provided food and water in the central chamber, while an oviposition substrate was in each of the two lateral chambers (Figure 3 ). We released 40 male and 40 female adults of reproductive age into the central chamber. Just prior to attachment of the oviposition substrate in one of the lateral chambers, we pipetted $2 \mu \mathrm{L}$ of pure methyl salicylate (Alfa Aesar, Ward Hill, MA, USA) onto the central upper portion of the set of substrate leaflets. This treatment produced a human-detectable scent. We counted insects directly after chamber attachment and again at 4,20, 24 , and $28 \mathrm{hr}$, and a final count and egg collection at $44 \mathrm{hr}$. We determined gender of beetles in both chambers after $44 \mathrm{hr}$. To control for the possibility of methyl salicylate incorporation into the plastic, containers were washed thoroughly after each experiment with warm soapy water, then rinsed twice with bleach, and then rinsed with $70 \%$ ethanol followed by another rinse with distilled water. The containers were then allowed to dry in sunlight for 24 hours. We replicated the experiment five times with new insects used in each replicate. Each replicate was set up in a glasshouse at noon, with the same arena orientation to avoid any influence of daylight on movement of insects into lateral chambers. After final assembly and initial tally of insect movement (within $2 \mathrm{~min}$ ), the arena was relocated to an environmental chamber as described above. We used the total number of insects in control or test lateral chambers and the number of intact eggs on oviposition substrates at the end of the experiment for data analysis.

2.6. Data Analysis. Experiments were set up following a completely randomized design. We used the paired $t$-test 


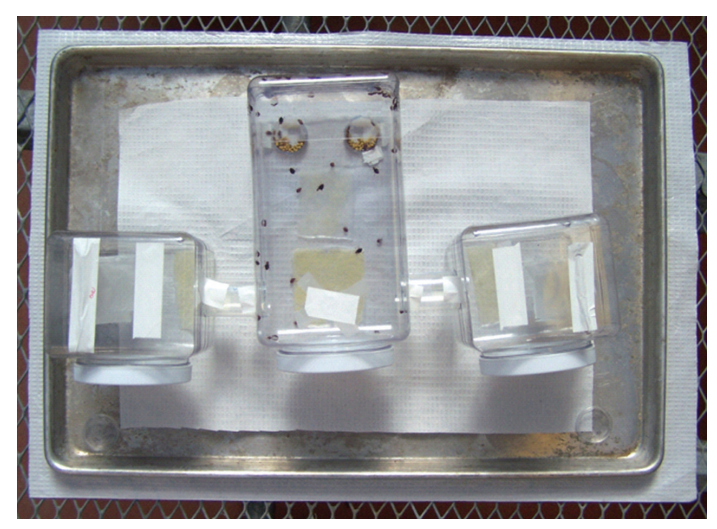

Figure 3: Three-chambered arena designed to measure beetle movement and oviposition in response to odors from methyl salicylate (MeSA). Beetles are visible in the central chamber.

to evaluate substrate type (textured versus smooth) on oviposition and cannibalism. We used one-way repeated measures analysis of variance (RM-ANOVA) using the Holm-Sidak method to evaluate the significance of crowding on oviposition and cannibalism. We also used a paired $t$ test to evaluate the influence of an attractant on insect movement and oviposition. Absolute data were square root transformed prior to analysis. Means were significantly different if $P<0.05$. We used SigmaStat 3.0.1 (Systat Software Inc., Richmond, CA, USA) for data analysis. All data presented herein represent nontransformed values.

\section{Results}

3.1. Influence of Substrate Type on Oviposition. Over the course of the experiment, we collected 120 and 79 egg masses from textured and smooth substrates, respectively. The mean \pm SEM number of eggs on textured and smooth substrates per cage per day was $19.0 \pm 2.9$ and $12.1 \pm 2.5$ eggs, respectively. Significantly more eggs were on textured substrate $(t=2.2, \mathrm{df}=16, P=0.046)$.

We observed cannibalism of eggs on both oviposition substrates. The mean \pm SEM number of eggs cannibalized on textured and smooth substrates per cage per day was not significant $(3.7 \pm 0.9$ and $3.0 \pm 0.8$ eggs, resp. $)(t=1.0$, $\mathrm{df}=15, P=0.32)$.

3.2. Influence of Crowding on Oviposition and Incidence of Cannibalism. We found that crowding of C. maculata adults (with males) in cages affected oviposition and egg cannibalism (Table 1). More eggs were laid by 10 females (with males) than by 50 or 100 females (with males) in experimental cages per day $(F=6.6$, df $=3,27 ; P=$ 0.002 ). The number of eggs laid by 25 females (with males) did not differ from other treatments. More eggs were eaten (cannibalized) by adults in cages with 25 females (with males) than with 100 females (with males). Cannibalism of eggs in the other treatments, 10 females (with males) and 50 females (with males), did not reveal any significant
TABLE 1: Effects of crowding (of C. maculata females with males) on the mean \pm SEM number of eggs laid and cannibalized per cage per day.

\begin{tabular}{lcc}
\hline Treatment & Eggs laid & Eggs cannibalized \\
\hline 10 females + males & $24.3 \pm 5.8^{\mathrm{a}}$ & $2.6 \pm 1.3^{\mathrm{ab}}$ \\
25 females + males & $10.4 \pm 4.5^{\mathrm{ab}}$ & $3.2 \pm 1.4^{\mathrm{a}}$ \\
50 females + males & $6.5 \pm 3.9^{\mathrm{b}}$ & $0.6 \pm 0.6^{\mathrm{ab}}$ \\
100 females + males & $1.7 \pm 1.6^{\mathrm{b}}$ & $0^{\mathrm{b}}$
\end{tabular}

Means \pm SEM followed by a different letter in a column are significantly different $(P<0.05)$.

TABle 2: Effects of crowding (of C. maculata females with or without males) on the mean \pm SEM number of eggs laid and cannibalized per cage per day.

\begin{tabular}{lcc}
\hline Treatment & Eggs laid & Eggs cannibalized \\
\hline 10 females + males & $9.2 \pm 2.8^{\mathrm{a}}$ & $3.3 \pm 1.6^{\mathrm{a}}$ \\
10 females & $10.3 \pm 5.1^{\mathrm{a}}$ & $0.1 \pm 0.1^{\mathrm{a}}$ \\
20 females + males & $9.7 \pm 3.4^{\mathrm{a}}$ & $3.1 \pm 2.0^{\mathrm{a}}$ \\
20 females & $9.3 \pm 4.3^{\mathrm{a}}$ & $0.5 \pm 0.5^{\mathrm{a}}$ \\
\hline
\end{tabular}

Means \pm SEM followed by the same letter in a column are not significantly different $(P>0.05)$.

differences from the other treatments. Crowding of $C$. maculata females (with or without males) at adult densities tested did not significantly affect oviposition rate or egg cannibalism (Table 2). No differences were detected between treatments consisting of 10 females with or without males and 20 females with or without males $(F=0.16$, $\mathrm{df}=3,27$; $P=0.9)$.

\subsection{Influence of Attractant on Insect Movement and Oviposi- tion. The attractant (methyl salicylate) affected the number of C. maculata adults moving in the arena (Table 3 ). More insects were in the test chamber than in the control chamber $(t=3.3$, df $=5, P=0.02)$. Males and females were moving into both chambers, as illustrated in Figure 4. The number of eggs laid in test and control chambers did not differ significantly $(t=0.47, \mathrm{df}=4, P=0.66)$.}

\section{Discussion}

The results described indicate that an easily accessible and inexpensive material can serve as an oviposition substrate for high volumes of egg collection. The use of hanging strips of tissue with a moderately textured surface provides a means of collecting multiple egg masses from groups of insects, while allowing assortive mating within the population. The hanging substrate provided refugia for resting, mating, and oviposition and was relatively easy to handle. Yellow or orange egg masses were easily visible on the white substrate and could be clipped from the leaves and transferred to another container or harvested for downstream processing. 


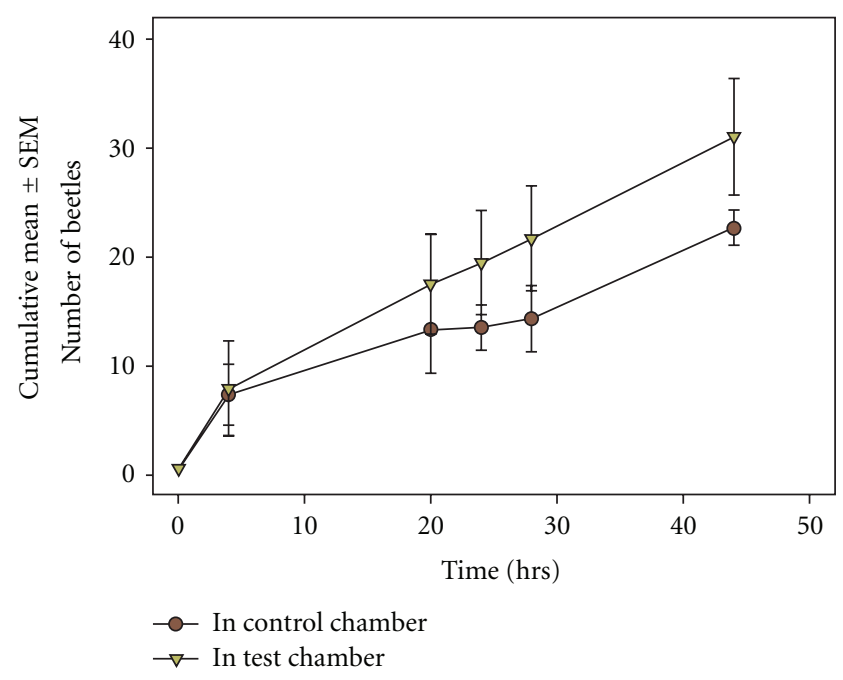

Figure 4: Cumulative mean \pm SEM number of beetles moving into control or test (MeSA-treated) lateral chamber of arena over time.

TABLE 3: Effects of attractant (methyl salicylate) on the mean \pm SEM number of C. maculata adults and eggs in control and test chambers of arena.

\begin{tabular}{lccc}
\hline Treatment & Adults per arena & Gender & Eggs laid \\
\hline $\begin{array}{l}\text { Control } \\
\text { chamber }\end{array}$ & $11.8 \pm 3.0^{\mathrm{a}}$ & $\begin{array}{c}11 \text { males: } 12 \\
\text { females }\end{array}$ & $55.2 \pm 27.1^{\mathrm{a}}$ \\
$\begin{array}{l}\text { Test } \\
\text { chamber }\end{array}$ & $16.3 \pm 4.4^{\mathrm{b}}$ & $\begin{array}{c}12 \text { males: } 19 \\
\text { females }\end{array}$ & $58.2 \pm 26.0^{\mathrm{a}}$ \\
\hline
\end{tabular}

Means \pm SEM followed by a different letter in a column are significantly different $(P<0.05)$.

We describe an oviposition choice assay for laboratory culture. C. maculata prefers to oviposit on leaves with trichomes rather than on smooth leaves in the field [16]. Another study of this predator utilized sulfite paper as an oviposition substrate [11]. Our study indicates that in laboratory culture, a smooth paper substrate is also less preferable. More egg masses and total eggs were deposited on the textured surface compared to the smooth surface. Repeated mating may be important for cultures of $C$. maculata, and mating in this species has been shown to be density dependent and enhanced by male isolation [21]. Our crowding experiments suggest that high population densities of C. maculata restrict mating and oviposition. While some density of insects below $50 / 2000 \mathrm{~mL}$ was shown to be more optimal for egg production than 100 or $200 / 2000 \mathrm{~mL}$, our tests do not identify a precise number or sex ratio per container to maximize egg production or minimize cannibalism. Additional replicated experiments may clarify this. It should be noted that the decrease in egg production in cages containing 100 or 200 individuals could represent cannibalism that was not detected. While every effort was made to visualize remnants of eggs that would indicate cannibalized egg masses, it is possible that eggs produced in those cages were completely consumed. Further research will help clarify this.
Regrettably, we did not extend our study to assess the influence of oviposition substrate and predator density on hatch rate and fertility of eggs. An examination of these lifehistory parameters is important to developing a mass rearing system, and we should consider them in a followup study.

Egg cannibalism by C. maculata is common in the laboratory and in the field $[22,23]$. Neonates of this species feed on conspecific eggs and apparently benefit from this behavior [23]. Some studies on this species suggest that larvae should be provided individual containment to curb cannibalism $[8,11]$. Because neonates remain on their egg mass for a period of time $(24-48 \mathrm{hr})$ after hatch, daily or other periodic collection of eggs will reduce egg plus neonate interactions as well as egg plus adult interactions. Our results did not identify a density or sex ratio that reduced cannibalism. Cannibalism was not reduced significantly on either of the substrates tested. It has been suggested that pubescence on leaves may interfere with foraging, thus plants with glandular trichomes "provide ovipositional refuges from cannibalism" [16]. Additional surfaces such as fabrics may provide oviposition substrates that reduce such losses. Our collections were daily, and research has shown that oviposition by C. maculata is periodic, with eggs laid primarily afternoon and before midnight [16]. Egg collection might be optimized by either varying timing or frequency of collections or by restricting substrate availability. The cage system described here is ideal for these experiments.

We attempted to answer the question of how to stimulate oviposition from groups of insects using the arena method and oviposition substrates. Ovipositional stimulants have been tested for this species. For example, extracts from wood [24] and extracts of Juniperus virginiana L. plants [25] were found to stimulate oviposition from individual females. Methyl salicylate is not an oviposition stimulant for C. maculata based on our preliminary results. Future research should evaluate a variety of other compounds at a range of concentrations.

Results presented here demonstrate a system that produces substantial quantities of insect biomass at defined stages of development. The cage system described yielded the desired quantity of eggs; a set of six cages with ten females per cage can supply 100-200 eggs per day on a continuous basis (results not shown). RNA extraction for gene expression requires specimens at identical developmental stage. Eggs and newly hatched larvae are the smallest stage of these insects, at roughly $200 \mu \mathrm{g}$ per individual. Because standard extraction kits utilize tissue samples $20-40 \mathrm{mg}$, a minimum quantity of 100 individuals per extraction sample is necessary. Furthermore, because it is more convenient to process samples of at least two at a time, a minimum quantity of 200 individuals is desirable. Researchers need to be able to culture candidate species in large quantities for largescale genetic sequencing or on small scales for individual pair mating and selective inbreeding. Facilitated by studies described here, we have collected nucleic acids from every life stage of C. maculata and selected isofemale strains. Further refinement of this system should improve oviposition and reduce cannibalism. Then we can potentially scale up this system for commercial mass rearing. 


\section{Acknowledgments}

The authors thank Jonathan Lundgren and Donald Weber for live insect stock and critical advice about setting up initial colonies. The authors extend appreciation to the laboratory technicians who provided assistance in completing this work, Catherine L. Smith and Fannie M. Byrd. They also thank Walker Jones, Kristine T. Edwards, and Louis S. Hesler for reviewing a previous version of this paper and providing helpful suggestions. The United States Government has the right to retain a nonexclusive, royalty-free license in and to any copyright of this paper. This paper reports the results of research only. Mention of a commercial or proprietary product does not constitute an endorsement of the product by the United States Department of Agriculture. USDA is an equal opportunity provider and employer.

\section{References}

[1] R. D. Gordon, "The Coccinellidae (Coleoptera) of America north of Mexico," Journal of the New York Entomological Society, vol. 93, no. 1, pp. 1-912, 1985.

[2] J. G. Lundgren, S. E. Moser, R. L. Hellmich, and M. P. Seagraves, "The effects of diet on herbivory by a predaceous lady beetle," BioControl Science and Technology, vol. 21, no. 1, pp. 71-74, 2010.

[3] T. E. Cottrell and K. V. Yeargan, "Effect of Pollen on Coleomegilla maculata (Coleoptera: Coccinellidae) population density, predation, and cannibalism in sweet corn," Environmental Entomology, vol. 27, no. 6, pp. 1402-1410, 1998.

[4] R. V. Hazzard, D. N. Ferro, R. G. V. Driesche, and A. F. Tuttle, "Mortality of eggs of the Colorado potato beetle (Coleoptera: Chrysomelidae) from predation by Coleomegilla maculata (Coleoptera: Coccinellidae)," Environmental Entomology, vol. 20, no. 3, pp. 841-848, 1991.

[5] S. J. Risch, D. Andow, and M. A. Altieri, "Agroecosystem diversity and pest control: data, tentative conclusions, and new research directions," Environmental Entomology, vol. 12, no. 3, pp. 625-629, 1983.

[6] M. P. Seagraves and K. V. Yeargan, "Importance of predation by Coleomegilla maculata larvae in the natural control of the corn earworm in sweet corn," Biocontrol Science and Technology, vol. 19, no. 10, pp. 1067-1079, 2009.

[7] Y. H. Atallah, "Ecological and nutritional studies on Coleomegilla maculata De Geer (Coleoptera: Coccinellidae). I. the effects of different population densities and sex ratios on oviposition," Journal of Economic Entomology, vol. 59, no. 5, pp. 1179-1180, 1966.

[8] B. C. Smith, "A technique for rearing coccinellid beetles on dry foods, and influence of various pollens on the development of Coleomegilla maculata lengi Timb. (Coleoptera: Coccinellidae)," Canadian Journal of Zoology, vol. 38, no. 6, pp. 10471049, 1960.

[9] E. W. Riddick and P. Barbosa, "Impact of Cry3A-Intoxicated Leptinotarsa decemlineata (Coleoptera: Chrysomelidae) and pollen on consumption, development, and fecundity of Coleomegilla maculata (Coleoptera: Coccinellidae)," Annals of the Entomological Society of America, vol. 91, no. 3, pp. 303307, 1998.

[10] R. B. Silva, I. Cruz, M. L. C. Figueiredo, and W. S. Tavares, "Development of Coleomegilla maculata De Geer (Coleoptera: Coccinellidae) with prey and artificial diet," Revista Brasileira de Milho e Sorgo, vol. 9, no. 1, pp. 13-36, 2010.
[11] T. M. Santos-Cividanes, A. C. R. dos Anjos, F. J. Cividanes, and P. C. Dias, "Effects of food deprivation on the development of Coleomegilla maculata (De Geer) (Coleoptera: Coccinellidae)," Neotropical Entomology, vol. 40, no. 1, pp. 112-116, 2011.

[12] D. C. Weber and J. G. Lundgren, "Effect of prior diet on consumption and digestion of prey and non-prey food by adults of the generalist predator Coleomegilla maculata," Entomologia Experimentalis et Applicata, vol. 140, no. 2, pp. 146-152, 2011.

[13] L. Pilorget, J. Buckner, and J. G. Lundgren, "Sterol limitation in a pollen-fed omnivorous lady beetle (Coleoptera: Coccinellidae)," Journal of Insect Physiology, vol. 56, no. 1, pp. 81-87, 2010.

[14] Y. Li, J. Ostrem, J. Romeis et al., "Development of a tier-1 assay for assessing the toxicity of insecticidal substances against Coleomegilla maculata," Environmental Entomology, vol. 40, no. 2, pp. 496-502, 2011.

[15] M. P. Seagraves and K. V. Yeargan, "Selection and evaluation of a companion plant to indirectly augment densities of Coleomegilla maculata (Coleoptera: Coccinellidae) in sweet corn," Environmental Entomology, vol. 35, no. 5, pp. 13341341, 2006.

[16] A. C. Staley and K. V. Yeargan, "Oviposition behavior of Coleomegilla maculata (Coleoptera: Coccinellidae): diel periodicity and choice of host plants," Environmental Entomology, vol. 34, no. 2, pp. 440-445, 2005.

[17] D. G. James, "Field evaluation of herbivore-induced plant volatiles as attractants for beneficial insects: methyl salicylate and the green lacewing, Chrysopa nigricornis," Journal of Chemical Ecology, vol. 29, no. 7, pp. 1601-1609, 2003.

[18] D. G. James, "Further field evaluation of synthetic herbivoreinduced plan volatiles as attractants for beneficial insects," Journal of Chemical Ecology, vol. 31, no. 3, pp. 481-495, 2005.

[19] J. Zhu and K. C. Park, "Methyl salicylate, a soybean aphidinduced plant volatile attractive to the predator Coccinella septempunctata," Journal of Chemical Ecology, vol. 31, no. 8, pp. 1733-1746, 2005.

[20] T. E. Cottrell, "Predation and cannibalism of lady beetle eggs by adult lady beetles," Biological Control, vol. 34, no. 2, pp. 159-164, 2005.

[21] J. P. Harmon, A. Hayden, and D. A. Andow, "Absence makes the heart grow fonder: isolation enhances the frequency of mating in Coleomegilla maculata (Coleoptera: Coccinellidae)," Journal of Insect Behavior, vol. 21, no. 6, pp. 495-504, 2008.

[22] T. E. Cottrell, "Predation by adult and larval lady beetles (Coleoptera: Coccinellidae) on initial contact with lady beetle eggs," Environmental Entomology, vol. 36, no. 2, pp. 390-401, 2007.

[23] I. Gagné, D. Coderre, and Y. Mauffette, "Egg cannibalism by Coleomegilla maculata lengi neonates: preference even in the presence of essential prey," Ecological Entomology, vol. 27, no. 3, pp. 285-291, 2002.

[24] M. I. Boldyrev, W. H. A. Wilde, and B. C. Smith, "Predaceous coccinellid oviposition responses to Juniperus wood," The Canadian Entomologist, vol. 101, no. 11, pp. 1199-1206, 1969.

[25] B. C. Smith, A. N. Starratt, and R. P. Bodnaryk, "Oviposition responses of Coleomegilla maculata lengi (Coleoptera: Coccinellidae) to the wood and extracts of Juniperus virginiana and to various chemicals," Annals of the Entomological Society of America, vol. 66, no. 2, pp. 452-456, 1973. 

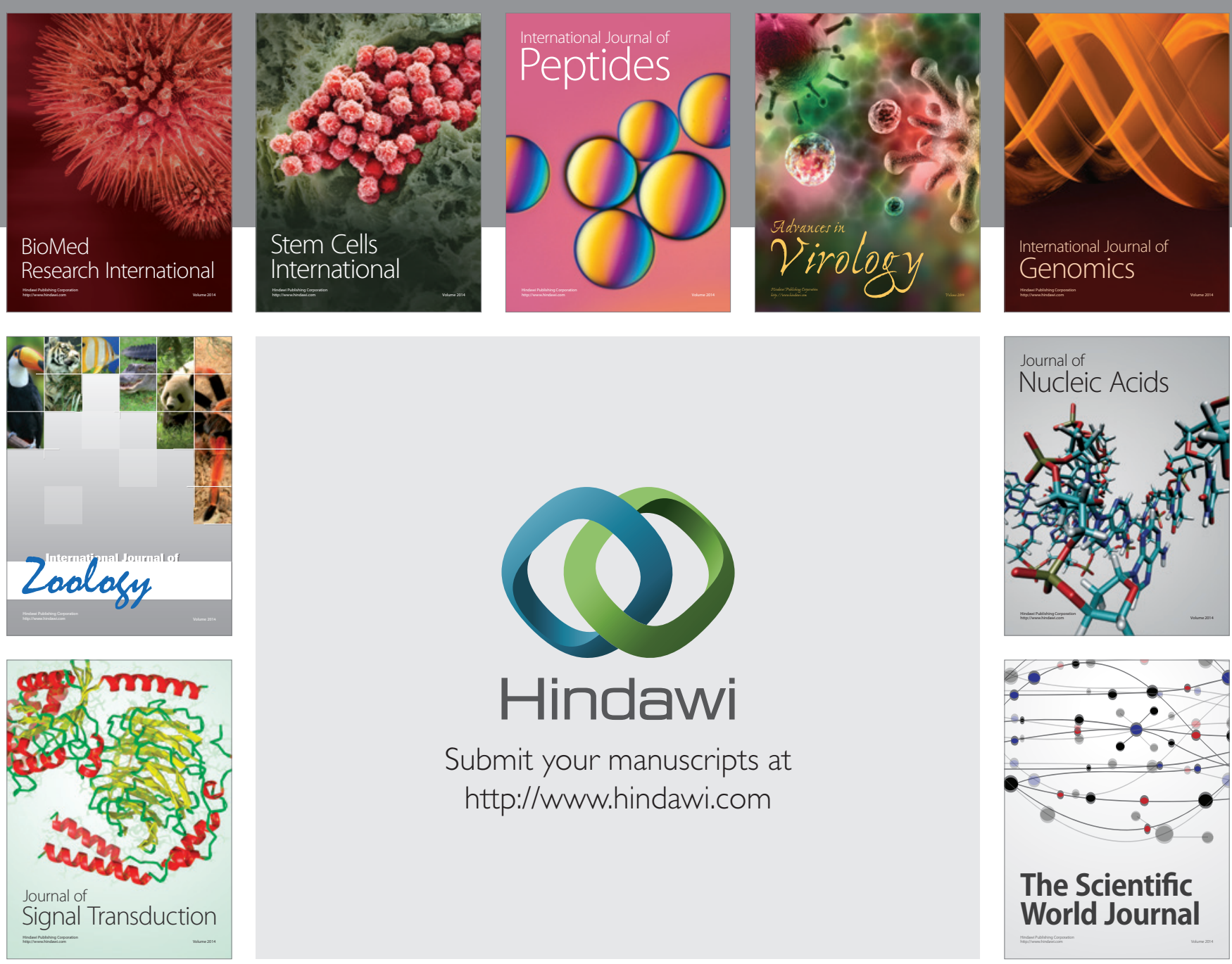

Submit your manuscripts at

http://www.hindawi.com
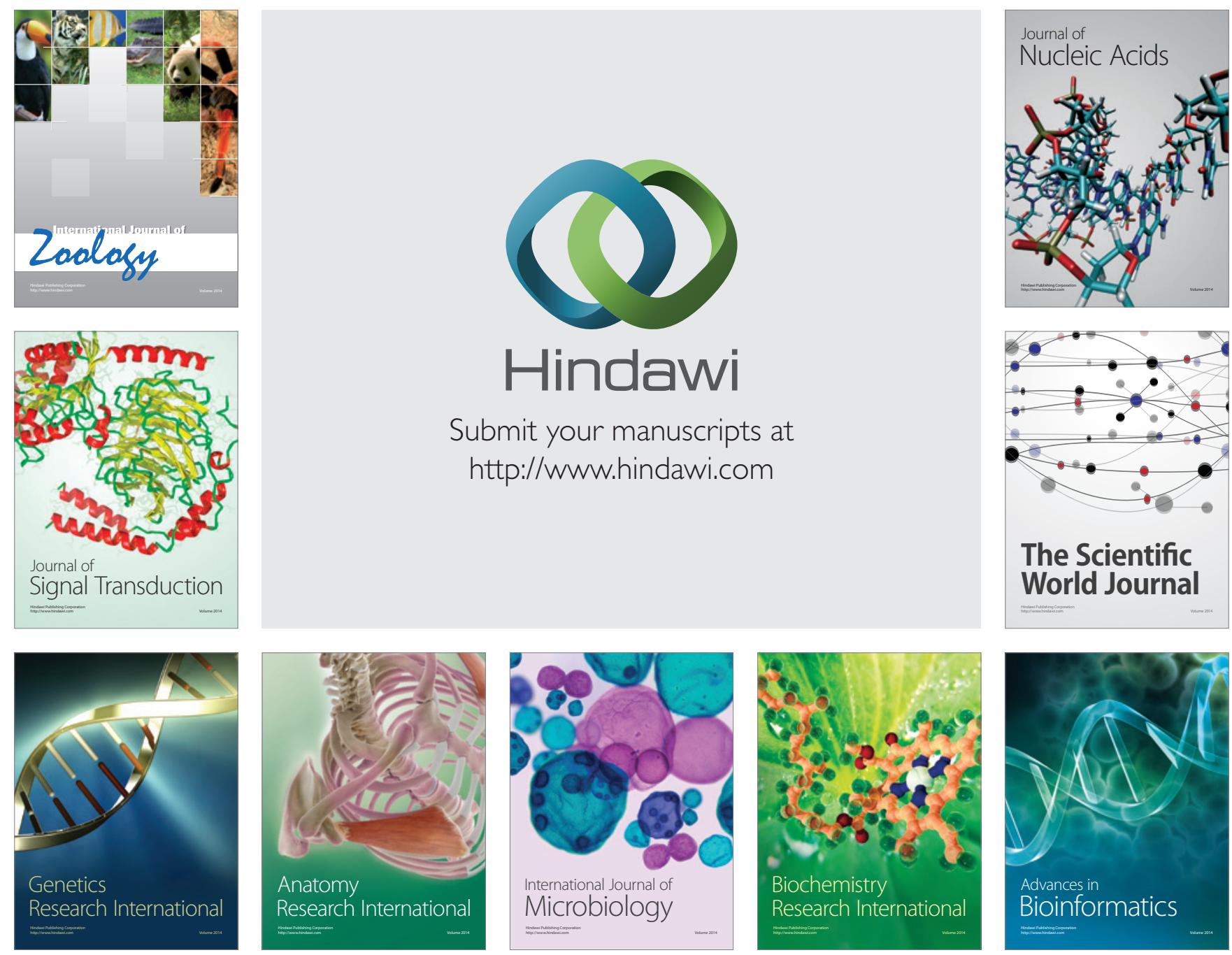

The Scientific World Journal
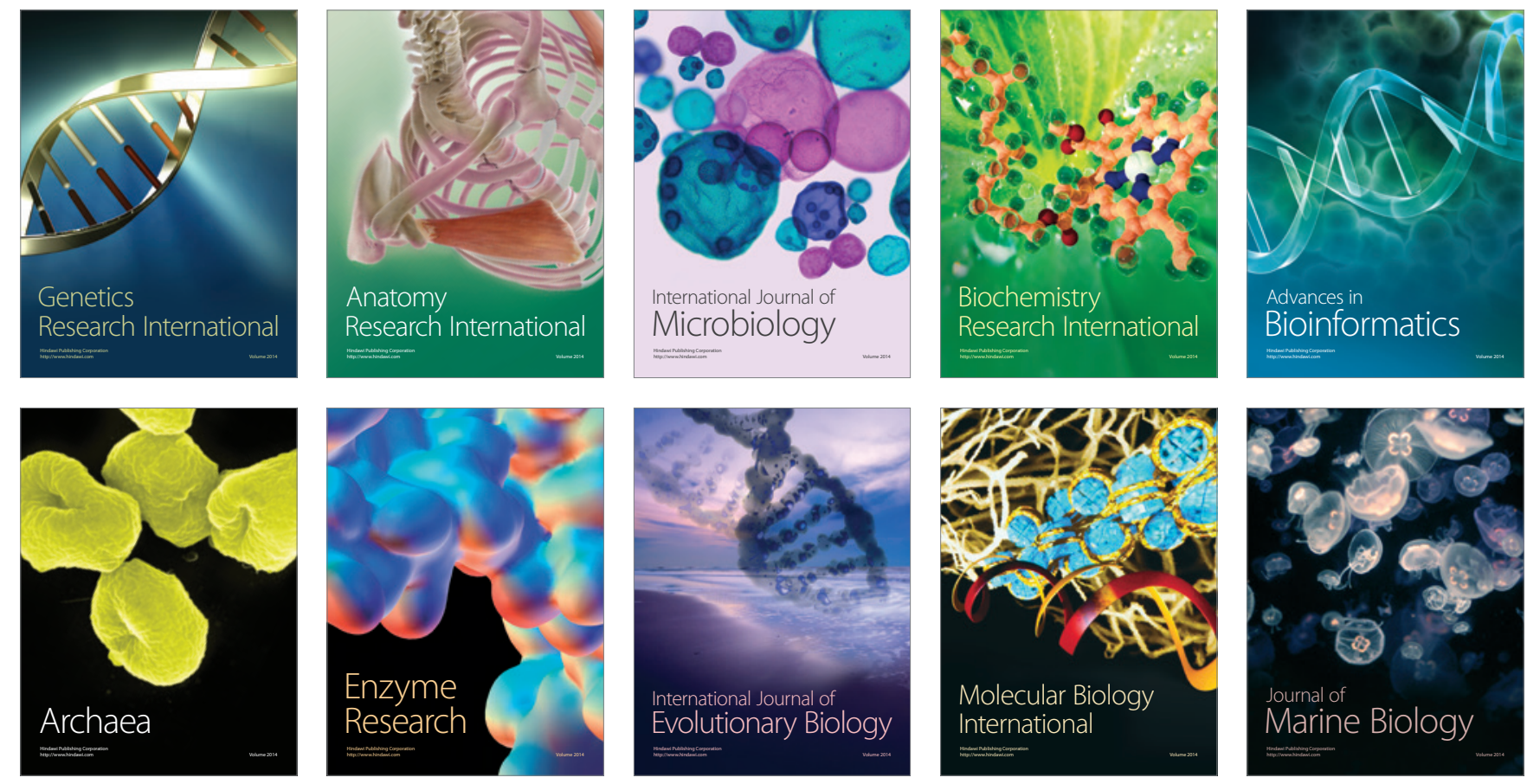